Irena Selišnik

\title{
ALJA ADAM, JANA DRAŠLER, KATARINA ŽUPEVC, NEŽA MREVLJE, ŠPELA KALČIĆ ŽENSKE NA ROBU.
}

Ljubljana: Institutum Studiorum Humanitatis, zbirka Ekskurzi, 2009.

160 strani.

Teksti v monografiji Ženske na robu iz interdisciplinarnih izhodišč spregovorijo o pogledih nadzora in panoptični oblasti nad žensko oziroma ženskostjo. Posamezni deli strnejo in med seboj povežejo ženske $\mathrm{z}$ obrobja družbe in izkušnje, o katerih redko slišimo. Monografija nam predstavi tako oprijemljive totalne institucije kot ujetosti v predpisane družbene norme, $\mathrm{v}$ katerih lahko prav tako prepoznamo izkušnjo totalnosti (zapor, samostan, cirkus, harem, koncept romantične ljubezni in mizoginost znanstvenega in umetniškega diskurza $\mathrm{v}$ 19. stoletju), ter nam pripoveduje o subverzivnem uporu žensk, katerega namen je redefinicija spolnih identitet, ki se v tekstih dogaja skozi recipročen ljubezenski odnos, subverzivne umetniške prakse 19 . stoletja, pozitiven odnos redovnic do staranja, abstrahiranje spola med izvajanjem cirkuške točke in s prizadevanjem zapornic, da svojo ženskost ohranijo z zavezanostjo skrbi v enospolnem svetu zapora. Struktura knjige je zaznamovana s številom tri. Iz sklenjene celote petih tekstov se namreč trije dotaknejo telesa in telesnosti (bolečina v cirkusu, razumevanje telesa pri uršulinkah, krotitev telesa $\mathrm{v}$ zaporu), trije pa so nastali kot rezultat terenskih raziskav v cirkusu, samostanu in zaporu, iz katerih nas neposredno nagovorijo intervjuvanke. Trije posežejo v zgodovino 19. stoletja in trije vzamejo pod drobnogled enospolni svet, kjer naj bi bila moška avtoriteta odsotna, vendar je disciplinska oblast patriarhalnega reda ponotranjena. Znotraj samega zbornika tako lahko znova in znova odkrivamo manjše sklenjene celote, ki se med seboj prekrivajo in tako tvorijo kalejdoskop tem.

$\mathrm{V}$ prvem poglavju nam Alja Adam predstavi koncept romantične ljubezni skozi mit tragične ljubezni med Orfejem in Evridiko. V njem problematizira razmerje moči in zlasti posledice idealizacije ženske $\mathrm{v}$ takšnem ljubezenskem razmerju. Kljub opisani brezizhodnosti 
tovrstnega ljubezenskega odnosa in njeni zatiralski naravi pa avtorica ponudi rešitev $\mathrm{v}$ razvoju recipročnega razmerja, ki naj bi uspešno razrešil dinamiko med obema akterjema in obetajoče naznanil večjo enakopravnost med spoloma. Avtorica nam skozi film Pred zoro predstavi odgovor na vprašanji, ali sta romantična ljubezen in feminizem sploh združljiva in kako naj bi recipročno razmerje tudi udejanjile in udejanjili. Iskanje ljubezni tako pomeni ne iskanje sebe v drugem, temveč iskanje samega sebe v razmerju do drugega, vzpostavljanju dveh enakovrednih entitet in ne v podrejanju.

$\mathrm{V}$ drugem poglavju Ukročevanje bolečine: (žensko) telo v cirkuški areni avtorice Jane Drašler se poglobimo v nenavadni/navadni svet cirkuškega vsakdana. J. Drašler nas na začetku članka spozna s fascinacijo družbe 19. stoletja nad podobo artistke oziroma akrobatke. Subverzivnost cirkuških nastopov je vznemirjala normativnost tedanje družbe in sem moramo prišteti tudi tedanje cirkuške artistke, ki so pod vprašaj postavljale podobe viktorijanske ženskosti. Enaki pa ostajajo nekateri razlogi za fascinacijo gledalca nad akrobatsko predstavo tudi sto let kasneje. Trenutek, ko akrobatka oziroma akrobat krši vse zakone težnosti za občinstvo in ko to uživa $\mathrm{v}$ spektaklu, akrobat abstrahira in pravzaprav žrtvuje samega sebe. Vračanje v resničnost ob koncu cirkuške točke tako pomeni bolečino, fizično pa tudi bolečino ob stiku $\mathrm{z}$ resničnim svetom, $s$ telesom.

Žensko telo je tako ključno tudi v članku Katarine Župevc. Avtorica $\mathrm{v}$ njem telesnost sooča $\mathrm{z}$ duhovnim svetom redovnic. $V$ članku raziskuje, koliko so redovnice $\mathrm{v}$ enospolnem svetu samostana ponotranjile moški pogled, ki kot zunanji svet vdira $\mathrm{v}$ eterični svet breztelesne duhovnosti. Dualizem med telesom in duhovnostjo ostaja prisoten $\mathrm{v}$ diskurzu redovnice. Presežen je ob vprašanjih staranja in zavrnjen ob poudarku redovnic na pomembnosti skladnosti telesnega in duhovnega, vendar še vedno navzoč $\mathrm{v}$ discipliniranju telesa in njegovega umeščanja v stereotipne normative. Avtorica raziskuje tudi velik simbolni pomen oblek uršulink, ki so več kot »navaden kostum«. Ker redovniška obleka štrli iz povprečnosti, pomeni nadzorovalni mehanizem, notranji in zunanji stalni pogled, ki se mu lahko izognejo le v varnem zavetju sestrske skupnosti. Sestrska skupnost sodobnih žensk bi v zunanjem svetu opravljala prav nasprotno funkcijo, ženske pa bi bile realne opazovalke, ki so ponotranjile 
moški pogled fantomskega drugega na ženskost. Hkrati pa varno zavetje skupnosti ne pomeni zaščite pred vsemi pogledi.

$\mathrm{V}$ prispevku »Ko ne vidiš trave tri leta« spoznamo življenje obsojenk v Zavodu za prestajanje kazni zapora Ig. Če je bila v primeru redovnic identifikacija $s$ totalno institucijo prostovoljna, pa temu v zaporu ni tako. Neža Mrevlje razkriva nemoč zapornic in njihove strategije preživetja. $\mathrm{V}$ zaporu ideologija kaznovanja in disciplinskega nadzora spregovori na najbolj brutalen način, oblast in nadzor sta tu še oprijemljivejša ter celo nujna in predpisana. $\mathrm{V}$ članku avtorica referira na Foucaulta in njegovo temeljno delo Nadzorovanje in kaznovanje ter nas najprej popelje skozi zgodovinski proces sprememb kaznovalne politike, ki se je od telesne kazni prenesla na kazen duha. Novi inženiring človeške duše v zaporu še vedno zadeva tudi telo, ki postane le fizično orodje za odvzem prostosti in tako tudi umestitev v ekonomijo odvzema pravic. N. Mrevlje se med drugim sprašuje tudi o smiselnosti cilja zapora kot prevzgojne institucije in smotrnosti kazenskih sankcij, o čemer so spregovorile njene intervjuvanke. Osrednjo vlogo $\mathrm{v}$ njihovih pripovedovanjih zavzema koncept časa, osrednje enote, $v$ kateri je bila kazen odmerjena, in strukturiranje časa, ki je ključno za osmišljanje bivanja. Zapornice se v času prestajanja kazni srečujejo tudi $z$ drugimi vprašanji, $z$ redefinicijo svojih družbenih vlog, ponotranjenjem panoptičnega nadzora in strategijami preživetja, ki med drugim pomeni tudi oklepanje ženskosti.

$\mathrm{V}$ zadnjem poglavju knjige se pred nami odpre svet orientalskih haremov ter kolonialni in mačistični pogled nanje. Špela Kalčić nas popelje v kolonialni svet 19. stoletja in dekonstruira zahodnjaški pogled na Orient, ki je tudi skozi umetnost utrjeval dominacijo zahodnega belega moškega. Haremi so bili prostori, ki so burili moško domišljijo in marsikaterega pisatelja spodbudili k njihovi upodobitvi, toda hkrati so bili tudi prostori, v katere je bil moškim vstop prepovedan. Moški slikarji so bili tako prisiljeni svoje podobe graditi na literarnih predlogah potopisov, ki so jih pisale ženske. Svoboda ustvarjanja je dopuščala, da so slikarji pri tem izživeli vse svoje spolnofantazmične predstave in domišljijo. Ustvarjalke so želele tovrstno podobo spodkopati, toda pri tem so bile tudi same ujete v norme spodobnosti in zahodne imperialno patriarhalne ideologije. Kot 
primer takšnega delovanja Š. Kalčić predstavi delo slikarke Henriette manskih žensk, ki so kljub ujetosti Browne, ki je v šestdesetih letih 19. v totalno institucijo našle načine, da stoletja francosko javnost razburila so ji prikrile del svoje intimnosti. s svojimi podobami harema. Njen naturalistični slog upodabljanja harema so kritizirali, saj ni več puščal prostora za domišljijo. Š. Kalčić se nato posveti Jeleni Dimitrijević, še eni prezrti avtorici - piski potopisov in romanov iz Srbije. Njena Pisma iz Niša, ki opisujejo prežitke muslimanske kulture v Srbiji, predvsem hareme, so tako v kanonih znanosti kakor tudi $\mathrm{v}$ tedanjem popularnem diskurzu ostala popolnoma prezrta. Njena literatura namreč predstavlja travmo, ki jo je treba potlačiti, da lahko nastane nova srbska nacija. Subverzivnost dejanja Jelene Dimitrijević se tako skriva v njenem boju za pravico do ustvarjanja, pa tudi za krog bralcev in bralk.
Zbornik Ženske na robu v strnjeni obliki predstavlja dosedanja obsežnejša dela raziskovalk (disertacija in diplomska dela), za katere bi bilo škoda, če bi ostala neobjavljena. Zaradi navezanosti na sodobne študije orientalizma, spola, sociologijo čustev in študije Foucaulta namreč operirajo s sodobnimi teoretskimi koncepti, ki jih utemeljijo na praktičnih in izvirnih primerih, ki so rezultat večmesečnega individualnega antropološkega terenskega raziskovalnega dela in tako zagotovo zapolnjujejo manko v slovenski znanstveni produkciji. S svojo interdisciplinarnostjo in inovativnostjo nagovarjajo najširši 